\title{
Compact Electrically tunable Waveplate Based on Liquid Crystal Photonic Bandgap Fibers
}

Wei, Lei; Alkeskjold, Thomas Tanggaard; Keller, Stephan Urs; Lindhard, Jonas Michael; Jensen, Helle Vendelbo; Nielsen, Kristian; Boisen, Anja; Bjarklev, Anders Overgaard

Published in:

Technical digest, CLEO/QELS

Publication date:

2009

Document Version

Publisher's PDF, also known as Version of record

Link back to DTU Orbit

Citation (APA):

Wei, L., Alkeskjold, T. T., Keller, S. U., Lindhard, J. M., Jensen, H. V., Nielsen, K., Boisen, A., \& Bjarklev, A. O. (2009). Compact Electrically tunable Waveplate Based on Liquid Crystal Photonic Bandgap Fibers. In Technical digest, CLEO/QELS IEEE.

\section{General rights}

Copyright and moral rights for the publications made accessible in the public portal are retained by the authors and/or other copyright owners and it is a condition of accessing publications that users recognise and abide by the legal requirements associated with these rights.

- Users may download and print one copy of any publication from the public portal for the purpose of private study or research.

- You may not further distribute the material or use it for any profit-making activity or commercial gain

- You may freely distribute the URL identifying the publication in the public portal 


\title{
Compact Electrically Tunable Waveplate Based on Liquid Crystal Photonic Bandgap Fibers
}

\author{
Lei Wei ${ }^{1}$, Thomas Tanggaard Alkeskjold ${ }^{2}$, Stephan Urs Keller ${ }^{3}$, Jonas Michael Lindhard ${ }^{4}$, Helle Vendelbo \\ Jensen $^{4}$, Kristian Nielsen ${ }^{1}$, Anja Boisen ${ }^{3}$ and Anders Bjarklev ${ }^{1}$ \\ ${ }^{1}$ DTU Fotonik, Department of Photonics Engineering, Technical University of Denmark, DK-2800 Lyngby, Denmark \\ ${ }^{2}$ Crystal Fibre A/S, Blokken 84, DK-3460 Birkerød, Denmark \\ ${ }^{3}$ DTU Nanotech, Technical University of Denmark, DK-2800 Lyngby, Denmark \\ ${ }^{4}$ DTU Danchip, Technical University of Denmark, DK-2800 Lyngby, Denmark \\ lewe@fotonik.dtu.dk
}

\begin{abstract}
A compact tunable waveplate based on negative dielectric liquid crystal photonic bandgap fibers is presented. The birefringence can be tuned electrically to work as a quarter-wave or a half-wave plate in the wavelength range $1520 \mathrm{~nm}-1580 \mathrm{~nm}$.

(C)2009 Optical Society of America

OCIS codes: (230.3720) Liquid-crystal devices; (060.5295) Photonic crystal fibers
\end{abstract}

\section{Introduction}

Liquid Crystal (LC) infiltrated Photonic Crystal Fibers (PCFs) have attracted significant interest in the past decade due to their unique optical properties and high sensitivity to thermal and electric field [1-7]. Since LCs normally have larger electro-optic effect than other high-index liquids, electrically driven Liquid Crystal filled Photonic BandGap (LCPBG) fiber devices for switching [3], or as long-period grating [7] with millisecond response time have been developed. Also, a continuously tunable birefringence controller with phase shift of $60^{\circ}$ by using a dualfrequency LCPBG fiber has been proposed [4]. Here, to our knowledge, we demonstrate the first compact electrically tunable waveplate realized in a negative dielectric LCPBG fiber device. The birefringence is tuned electrically to give both a quarter-wave and a half-wave plate in the wavelength range $1520 \mathrm{~nm}-1580 \mathrm{~nm}$.

\section{Experimental results}

The cross section of the device is shown in Fig. 1(a). A LCPBG fiber is mounted between two v-grooves fabricated in a silicon substrate by standard UV lithography and $\mathrm{KOH}$ wet etching techniques. 200nm gold electrodes are deposited on the side walls of the grooves, forming a set of electrodes, which fix the fiber at four orthogonal corners relative to the core. The electrode patterning of this device is achieved by using electrodeposition of Eagle $2100 \mathrm{ED}$ photoresist on top of the gold layer with subsequent UV lithography, development, gold and titanium etch, and photoresist stripping. The electrodes are electrically isolated from the silicon substrate by a thermal oxide layer with the thickness of $2 \mu \mathrm{m}$, and a $10 \mathrm{~nm}$ titanium layer is used as an adhesion layer between the gold layer and the oxide. SU-8 supporting structures are built up to keep a certain space between the bottom and top chips, and to make sure they are parallel enough (e.g. the space between electrode 1 and 3 , or electrode 2 and 4 is $\mathrm{D} / 1.414=88.4 \mu \mathrm{m}$, where $\mathrm{D}=125 \mu \mathrm{m}$ is the outer diameter of the fiber) during the assembly which is sealed with epoxy afterwards.

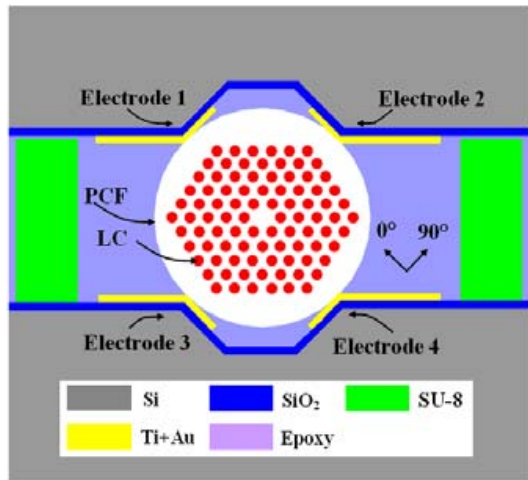

(a)

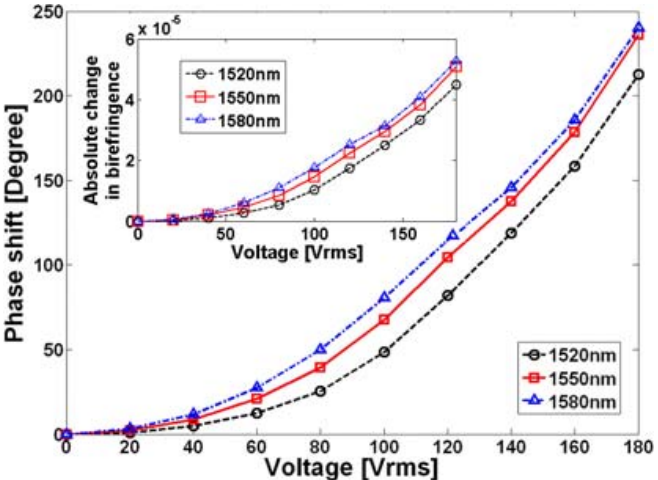

(b)

Fig. 1(a). The cross section of the LCPBG fiber device. Fig. 1(b). Electrically induced phase shift of this LCPBG device for different voltages in the wavelength range $1520 \mathrm{~nm}-1580 \mathrm{~nm}$. The inset shows the electrically induced absolute change in birefringence of this LCPBG device as a function of voltage. 


\section{CMW4.pdf}

The fiber used in the experiments is a Large Mode Area PCF (LMA-13, Crystal Fibre A/S), with a solid core surrounded by 5 rings of air holes arranged in a triangular lattice. The hole diameter, inter hole distance and outer fiber diameter are $4.3 \mu \mathrm{m}, 8.5 \mu \mathrm{m}$ and $125 \mu \mathrm{m}$, respectively. A negative dielectric LC MLC-6608 (Merck, Germany) with a dielectric anisotropy $\Delta \varepsilon=-4.2$ is infiltrated for $20 \mathrm{~mm}$ of the length of the fiber by using capillary forces.

When an electric field is applied to the LCPBG fiber, the LC reorients depending on the applied voltage. The two orthogonally polarized guiding modes experience different refractive indices compared to the case in which the field is off and this introduces a phase shift between them. To demonstrate the electrically induced phase shift and correspondingly induced birefringence, a polarized and tunable laser source operating from $1520 \mathrm{~nm}$ to $1620 \mathrm{~nm}$ is connected to this LCPBG device through a polarization analyzer. A polarization controller is used to find a polarization state with a transmission spectrum between the maximum and minimum states. The polarization analyzer launches the light in the LCPBG device and resolves the output light into the Stokes parameters, which is then plotted on the surface of the Poincaré sphere. Any change inducing a phase shift between the orthogonal polarizations in the fiber device results in a rotation on the sphere. The device is driven by a $1 \mathrm{kHz}$ sine wave in bipolar mode. The total insertion loss of this device in the whole test system is $3.2 \mathrm{~dB}$, and the activation loss under 180 Vrms is less than $1 \mathrm{~dB}$. During the experiments, the working temperature of this device is stabilized at $25^{\circ} \mathrm{C}$.

Figure 2(a)-(d) show the phase shift on the Poincaré sphere when a driving voltage of $0 \mathrm{Vrms}, 100 \mathrm{Vrms}$, $150 \mathrm{Vrms}$ and $180 \mathrm{Vrms}$ is applied to this LCPBG device by launching $1550 \mathrm{~nm}$ polarized laser light. The red line represents the polarization states in the near part of the sphere and the blue line represents the polarization states on the opposite side of the sphere. Figure 1(b) plots the electrically induced phase shift and the inset of Fig. 1(b) plots the corresponding birefringence change of this LCPBG device as a function of voltage in the wavelength range $1520 \mathrm{~nm}-1580 \mathrm{~nm}$. A phase shift of $212.7^{\circ}$ is obtained by applying $180 \mathrm{Vrms}$, which gives a birefringence change of $4.17 \times 10^{-5}$ at $1520 \mathrm{~nm}$ by the relation given in [4]. More phase shift and birefringence are observed when an input signal with a longer wavelength is launched, e.g. a phase shift of $236.2^{\circ}$ and $240.1^{\circ}$, and a change in birefringence of $4.79 \times 10^{-5}$ and $5.09 \times 10^{-5}$ are obtained for $1550 \mathrm{~nm}$ and $1580 \mathrm{~nm}$, respectively. Concerning the birefringence control, a higher degree of tunable birefringence can be achieved if a PCF with a smaller structure is used.

In conclusion, we have fabricated and experimentally demonstrated a compact electrically tunable all-in-fiber waveplate working in the wavelength range $1520 \mathrm{~nm}-1580 \mathrm{~nm}$ based on a PCF infiltrated with a negative dielectric anisotropy LC. The four orthogonal groove electrodes can be connected in different electrode configurations corresponding to a rotatable direction of electric field, and therefore, give the potential for realizing an optical axis rotatable waveplate with electrically tunable birefringence.

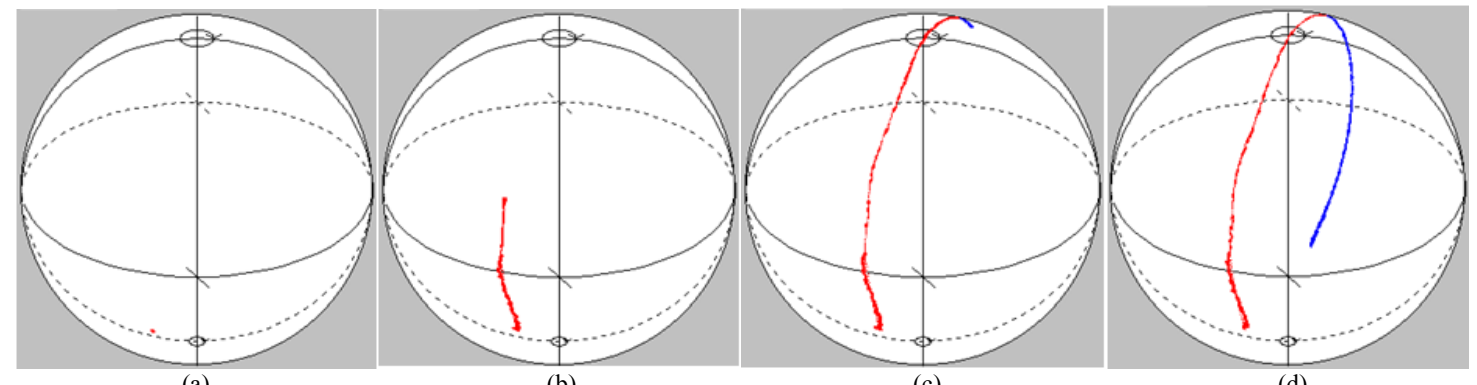

(a)

(b)

(c)

(d)

Fig. 2. Phase shift on the Poincaré sphere when a driving voltage of (a) $0 \mathrm{Vrms}$, (b) $100 \mathrm{Vrms}$, (c) $150 \mathrm{Vrms}$, (d) $180 \mathrm{Vrms}$ is applied to this LCPBG device by launching $1550 \mathrm{~nm}$ polarized laser light.

\section{References}

[1] T. T. Larsen, A. Bjarklev, D. S. Hermann, and J. Broeng, "Optical devices based on liquid crystal photonic bandgap fibres," Opt. Express 11, 2589-2596, (2003).

[2] F. Du, Y. Q. Lu and S.-T. Wu, "Electrically tunable liquid-crystal photonic crystal fiber," Appl. Phys. Lett. 85, 2181-2183, (2004).

[3] M. W. Haakestad, T. T. Alkeskjold, M. D. Nielsen, L. Scolari, J. Riishede, H. E. Engan and A. Bjarklev, "Electrically tunable photonic bandgap guidance in a liquid crystal filled photonic crystal fiber", IEEE Photonics Technology Letters, Vol. 17, 819-821, (2005).

[4] L. Scolari, T. T. Alkeskjold, J. Riishede, A. Bjarklev, D. S. Hermann, A. Anawati, M. D. Nielsen, and P. Bassi, "Continuously tunable devices based on electrical control of dual-frequency liquid crystal filled photonic bandgap fibers," Opt. Express 13, 7483-7496, (2005).

[5] D. C. Zografopoulos, E. E. Kriezis and T. D. Tsiboukis, "Tunable highly birefringent bandgap-guiding liquid crystal microstructured fibers", J. Lightwave Tech. 24, 3427-3432, (2006).

[6] T. R. Wolinski, K. Szaniawska, S. Ertman, P. Lesiak, A.W. Domanski, R. Dabrowski, E. Nowinowski-Kruszelnicki and J. Wojcik, "Influence of temperature and electrical fields on propagation properties of photonic liquid-crystal fibres", Meas. Sci. Technol., Vol.17, 985-991, (2006). [7] D. Noordegraaf, L. Scolari, J. Lægsgaard, L. Rindorf, and T. T. Alkeskjold, "Electrically and mechanically induced long period gratings in liquid crystal photonic bandgap fibers," Opt. Express 15, 7901-7912, (2007). 